\title{
Simultaneous application of AMMI measures and yield for stability analysis of wheat genotypes evaluated under irrigated late sown conditions of Central Zone of India
}

\author{
Ajay Verma* \\ ICAR-Indian Institute of Wheat and Barley Research, Karnal-132001 (Haryana), India \\ G.P. Singh \\ ICAR-Indian Institute of Wheat and Barley Research, Karnal-132001 (Haryana), India \\ ${ }^{*}$ Corresponding author. E mail. ajay.verma1@icar.gov.in
}

\author{
Article Info \\ https://doi.org/10.31018/ \\ jans.v12i4.2391 \\ Received: October 5, 2020 \\ Revised: November 16, 2020 \\ Accepted: November 21, 2020
}

\section{How to Cite}

Verma A. and Singh G.P. (2020). Simultaneous application of AMMI measures and yield for stability analysis of wheat genotypes evaluated under irrigated late sown conditions of Central Zone of India. Journal of Applied and Natural Science, 12 (4): 541 - 549. https://doi.org/10.31018/jans.v12i4.2391

\begin{abstract}
Reports on biased interpretation for the stability of the genotypes under AMMI analysis, considering only the first two interaction principal components, has been observed in recent past. Simultaneous use of yield and stability of genotypes in a single measure had been advocated for identification of highly productive and broadly adapted genotypes. The performance of superiority index, allowed variable weighting mechanism for yield and stability, has been compared with AMMI based measures. For the first year (2018-19) Superiority index, weighting 0.65 and 0.35 for yield and stability, found UAS3002, MP3336 and HI1633 as of stable performance with high yield. Recent analytic measures the relative proportion of genotypic value (PRVG) and Harmonic mean of the relative proportion of genotypic value (MHPRVG) selected CG1029, HI1634 and HD2932 wheat genotypes. Indirect relations were expressed by Superiority Index (SI) with other stability measures. Superiority index saw stable performance along with high yield of HD2864 and HI1634 for the second year 2019-20. PRVG as well as MHPRVG measures observed suitability of CG1029 and HD2864 while MP3336 as unstable wheat genotypes. Values of SI measure had expressed only indirect relations of high degree with stability measures except with yield, PRVG and MHPRVG values. Stability measures by the simultaneous use of AMMI and yield would be more meaning full and useful as compared to measures consider either the AMMI or yield of genotypes only.
\end{abstract}

Keywords: AMMI analysis, ASV, Biplot graphs, EV, SI, SSI, SIPC, Za

\section{INTRODUCTION}

AMMI analysis retains most of the genotype $x$ environment interaction pattern in the first interaction principal component axis (IPCA) resulting from the singular value decomposition (SVD) of the non-additive effects matrix, while most of the random error has been retained as noise in the last IPCAs (Balestre et al., 2009; Gauch, 2013; Adjebeng et al., 2017; Bocianowski et al., 2019; Veenstra et al., 2019). Moreover, under AM$\mathrm{MI}$ analysis usage, there would be a biased interpretation regarding the stability of the genotypes for instances with the low proportion of the variance explained by first interaction principal component IPCA1 (Zali et al., 2012; Bornhofen et al., 2017; Oyekunle et al., 2017). Weighted Average of Absolute scores (WAASB), the quantitative stability measure was found to be an important statistical tool for identifying highly productive and broadly adapted genotypes (Olivoto, 2018). The genotype with the lowest WAASB value is considered the most stable, that is, the one that deviates least from the average performance across environments (Olivoto, 2019). For the selection of promising genotypes, a superiority index, i.e. combine high yield and stability at the same time allowed weighting mechanism for yield and stability (WAASB) (Olivoto et al., 2019). The present study was planned to validate the relationships between WAASBY and other stability measures, as per AMMI model, of wheat genotypes evaluated under multi environmental trials in the Central Zone of India under restricted irrigated timely sown trials in recent past.

\section{MATERIALS AND METHODS}

The Central zone of India is well known for the premium quality of wheat, flour and other products. States of Madhya Pradesh, Chhattisgarh, Gujarat, Rajasthan (Kota and Udaipur divisions) and Jhansi division of Uttar Pradesh comprised this zone. Ten advanced promising wheat genotypes fifteen locations and five 
genotypes at sixteen locations were evaluated under field trials during 2018-19 and 2019-20 cropping seasons respectively. Field trials were conducted at research centers in randomized complete block designs with three replications. Recommended agronomic practices were followed to harvest good yield. Details of genotype parentage along with environmental conditions were reflected in tables 1 and 2 for ready reference. Stability measure Weighted Average of Absolute Scores has been calculated as

$$
\text { WAASB }=\sum_{k=1}^{p}\left|I P C A_{i k} \times E P_{k}\right| / \sum_{k=1}^{p} E P_{k}
$$

where $W A A S B_{i}$ is the weighted average of absolute scores of the ith genotype (or environment); $\operatorname{IPCA}_{i k}$ is the score of the ith genotype (or environment) in the $k$ th IPCA, and $\mathrm{EP}_{k}$ is the amount of the variance explained by the $k$ th IPCA. The genotype with the lowest WAASB value is considered the most stable, that is, the one that deviates least from the average performance across environments. Superiority index has been put forward that allows weighting between yield and stability measure WAASB index to select genotypes that combine high performance and stability as

$$
\text { WAASBY }=\frac{\left(r G_{i} \times \theta_{Y}\right)+\left(r W_{i} \times \theta_{S}\right)}{\left(\theta_{Y}+\theta_{S}\right)}
$$

where $r G_{i}$ and $r W_{i}$ are the rescaled values for yield and, respectively, for the $i$ th genotype; $G_{i}$ and $W_{i}$ are the yields and the WAASB values for ith genotype. SI superiority index for the ith genotype that weights between yield and stability, and $\theta Y$ and $\theta S$ are the weights for yield and stability assumed to be of order 65 and 35 respectively in this study,

Averages of the squared eigenvector values

$$
\mathrm{EV}=\sum_{n=1}^{N} \lambda_{\text {in }}^{2} / n
$$

Zobel (1998)

Sums of the absolute value of the IPC scores

$$
\operatorname{SIPC}=\sum_{n=1}^{N} \lambda_{n}^{0.5} \gamma_{i n}
$$

AMMI stability Value

$$
\mathrm{ASV}=\left[\left(\frac{S S I P C 1}{\operatorname{SIPC2} 2} P C I\right)^{2}+(P C 2)^{2}\right]^{1 / 2}
$$

Purchase (2000)

AMMI based stability parameter

$$
\text { ASTAB }=\sum_{n=1}^{n} \lambda_{n} \gamma_{n i}^{2}
$$

Rao and Prabhakaran (2005)

ASV1

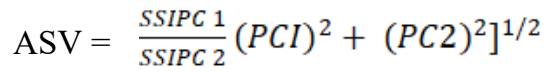

Zali et al. (2012)
Modified AMMI stability Value

$$
M A S V=\sqrt{\sum_{n=1}^{N-1} \frac{S S I P C_{n}}{S I P C_{n+1}}\left(P C_{n}\right)^{2}+\left(P C_{n+1}\right)^{2}}
$$

Zali et al. (2012)

Absolute value of the relative contribution of IPCs to the interaction

$$
\mathrm{Z}_{\mathrm{a}}=\sum_{n=1}^{N}\left|\lambda_{n} \gamma_{i n}\right|
$$

Zali et al. (2012)

MASV1

$$
\text { MASV1 }=\sqrt{\sum_{n=1}^{N-1}\left(\frac{S S I P C_{n}}{S S I P C_{n+1}} P C_{n}\right)^{2}+\left(P C_{n+1}\right)^{2}}
$$

Ajay et al. (2019)

Relative performance of genotypic values across environments

$P R V G_{i j}=V G_{i j} / V G_{i} \quad$ Resende and Durate (2007) Harmonic mean of Relative performance of genotypic values

MHPRVG $_{i .}=$ Number of environments $/ \quad \sum_{j=1}^{k} \frac{1}{P R V G_{i j}}$

Resende and Durate (2007)

Superiority Index

WAASBY or $S \mathrm{I}=\frac{\left(r G_{i} \times \theta_{Y}\right)+\left(r W_{i} \times \theta_{S}\right)}{\left(\theta_{Y}+\theta_{S}\right)}$

Olivato et al. (2019)

AMMI analysis was performed using AMMISOFT version 1.0, available at https://scs.cals.cornell.edu/ people/ hugh-gauch/ and SAS software version 9.3. Stability measures had been compared with recent analytic measures of adaptability calculated as the relative performance of genetic values (PRVG) and harmonic mean based measure of the relative performance of the genotypic values (MHPRVG) for the simultaneous analysis of stability, adaptability and yield (Resende and Durate, 2007).

\section{RESULTS AND DISCUSSION}

\section{First-year of study (2018-19)}

AMMI analysis: AMMI model comprised of additive main effects of genotype and environment and the multiplicative effect of GxE interaction, can explain more information compared to other methods (Zhang et al., 1988). AMMI models are generally called AMMI (1), AMMI (2), .. AMMI (n), depending on the number of principal components used to study the interaction (Gauch 2013). AMMI stability measures permit to evaluate yield stability after reduction of the noise from the GxE interaction effects. Highly significant effects of the environment $(E)$, genotypes $(G)$ and GxE interaction were observed. Significant environments explained about $79.5 \%$ of the total sum of squares due to treatments indicating that diverse environments caused most of the variations in genotypes yield. Moreover, up 
to $80 \%$ contribution of environmental effects is reported in sugarcane crop (Ramburan et al., 2011). Genotypes explained only $2.9 \%$ of the total sum of squares, whereas GxE interaction accounted for $9.4 \%$ of treatment variations in yield (Table 3). Higher GxE interaction sum of squares than to genotypes indicated the presence of genotypic differences across environments and complex GxE interaction for wheat yield. Larger GxE interaction effects over genotype, making selection of stable genotype difficult (Bocianowski et al., 2019). Further partitioning of GxE interactio7 mn through the AMMI model revealed that the first seven multiplicative terms (IPCA1, IPCA2, IPCA3 and IPCA7) of AMMI were significant and explained $32.7 \%$, $21.2 \%, 19.2 \%, 8.9 \%, 6.7 \%, 4.9 \%$ and $4.6 \%$ of interaction sum of squares, respectively. Total of significant components were $98.2 \%$ and remaining $1.8 \%$ is the residual or noise, which is not interpretable and thus discarded (Ajay et al., 2019).

Stability measures: Least value of absolute IPCA1 expressed by G3, G7, G5 and G4 possessed the higher value (Table 5). Low values of (EV) associated with stable genotype accordingly, the genotype G10 followed by G1 and G2 had stability and genotype G3 had the maximum value of EV measure. The lower value SIPC measure identified $\mathrm{G} 10$ followed by G6 and G3 as the most stable genotypes, whereas G4 would be of least stable behaviour. Za measure considered the absolute value of the relative contribution of IPCs to the interaction revealed G10, G7 and G3 genotypes as most stable in descending order of stability, whereas G4 genotype with the least stability. ASTAB measure observed genotypes G1, G10 and G6 as most stable and genotype G4 was least stable in this study. ASV measure showed that genotypes G7, G1, G6 possessed lower values would express stable performance and G4 be of least stable type. Values of ASV1 selected G7, G1, G6 for their stable behaviour whereas $\mathrm{G} 4$ would express unstable performance. Measures MASV and MASV1 consider all significant IPCAs. Values of MASV showed that the genotypes G10, G9 and G6 were most stable and G10, G9 and G8 would be stable by MASV1measure respectively. The lower values of WAASB associated with stable nature of genotypes as G10, G7, G3 expressed lower values and would stable genotypes for considered locations of the zone at the same time maximum value obtained by $\mathrm{G} 4$, that is, the one that deviates maximum from the average performance across environments (Olivoto et al., 2019). The lower value of Superiority index had observed for G5, G8 and $\mathrm{G} 1$, whereas large value expressed by G6. Genotypes G6, G3 and G4 were identified for their more stable yield performance by MHPRVG and PRVG measure selected G6, G3, G4 along with least stable yield of $\mathrm{G} 5$. Maximum yield expressed by $\mathrm{G} 6$ followed by $\mathrm{G} 8$ and $\mathrm{G} 1$ as good variation observed from 52.9 to $44.2 \mathrm{q} /$ ha among genotypes.
Simultaneous ranks of genotypes as per AMMI based stability and yield: The stability alone by itself is not a desirable selection criterion as these stable genotypes may not be high yielders, for which simultaneous consideration of yield of wheat genotypes and stability in a single nonparametric index is essential (Kang 1993; Farshadfar et al., 2008). Simultaneous Selection Index proposed by Farshadfar et al., (2011) also referred to as genotype stability index (GSI) or yield stability index (YSI) computed by adding the ranks of stability measure and an average yield of wheat genotypes.

As per the least values of ranks for IPCA1 measure, CG1029, HD2932 and HI1633 were considered as stable with high yield, whereas high values suggested as the least stable yield for MP4010 genotype (Table 7). Value of EV measure identified HD2932, HI 8807 and CG 1029 by whereas measure SPIC favoured HI8807, HD2932 and HI1634 genotypes. Wheat genotypes HI 8807, HI1634, HI1633 possessed lower value of $\mathrm{Za}$ measure while large value by MP4010. Composite measures MASV selected HI 8807, HD 2932, HI1634 and as per values of MASV1 as HI8807, HI1634, HI8808 genotypes of choice for these locations of the zone at the same time unstable performance of MP4010 and UAS 3002. Values of least magnitude of ASV observed for HD932, HI1633 and HI1634 wheat genotypes and ASV1 pointed towards CG1029, HD2932, HI1633. In the present study, all measures identified genotypes CG1029, HD 2932 and HI1633 as stable and high yielders. Suitability of HI8807, HI1633 and MP 3336 genotypes was observed by WAASB measure. Superiority index while weighting 0.65 and 0.35 for yield and stability found UAS3002, MP3336 and HI1633 as of stable performance with high yield. Moreover, the average yield of genotypes ranked CG1029, HI1634 and HD2932 as of the order of choice. PRVG and MHPRVG measures settled for CG1029, HI1634 and HD2932 wheat genotypes.

Biplot graphs :Loadings of stability measures as per first two significant principal component analysis (PCA) for evaluated wheat genotypes are reflected in table 9. The first two PCAs explained $79.9 \%$ of the variation of the original variables (Fig. 1). Za clustered with SIPC, MASV, MASV1, ASTAB measures. The separate group comprises of yield with ASV, IPCA1, ASV1, PRVG and MHPRVG measures. WAASB and SI measures maintained a distance from other stability measures and observed as outliers in different quadrants.

Association analysis among stability measures: Correlation coefficient values were computed for each pair of measures to have an idea of association analysis among other stability measures. Mean yield showed highly significant positive correlations with MASV, MASV1, MHPRVG and PRVG (Table 11). At the same time, other measures expressed negative 
Verma A. and Singh G.P. / J. Appl. \& Nat. Sci. 12(4): 541 - 549 (2020)

Table 1. Parentage details of genotypes and environmental conditions (2018-19).

\begin{tabular}{lllllll}
\hline Code & Genotype & Parentage & Environments & Latitude & Longitude & Altitude \\
\hline G 1 & HD 2932 & (KAUZ/STAR//HD2643) & Anand & $22^{\circ} 33^{\prime} \mathrm{N}$ & $72^{\circ} 56^{\prime} \mathrm{E}$ & 39 \\
G 2 & HD 2864 & (DL509-2/DL377-8) & Bardoli & $21^{\circ} 7^{\prime} \mathrm{N}$ & $73^{\circ} 6^{\prime} \mathrm{E}$ & 22 \\
G 3 & MP 3336 & (HD 2402/GW 173) & Junagarh & $21^{\circ} 30^{\prime} \mathrm{N}$ & $70^{\circ} 27^{\prime} \mathrm{E}$ & 90 \\
G 4 & MP 4010 & (ANGOSTURA 88) & S.K.Nagar & $21^{\circ} 18^{\prime} \mathrm{N}$ & $72^{\circ} 85 \mathrm{E}$ & 11 \\
G 5 & CG 1029 & (HW 2004/PHS725) & Vijapur & $23^{\circ} 33^{\prime} \mathrm{N}$ & $72^{\circ} 45^{\prime} \mathrm{E}$ & 129.4 \\
G 6 & UAS 3002 & (RAJ4083/DWR195//HI 977) & Sanosara & $21^{\circ} 72^{\prime} \mathrm{N}$ & $71^{\circ} 76^{\prime} \mathrm{E}$ & 89 \\
G 7 & HI 1633 & (GW-322 / PBW-498) & Gwalior & $26^{\circ} 13^{\prime} \mathrm{N}$ & $78^{\circ} 10^{\prime} \mathrm{E}$ & 213 \\
G 8 & HI 1634 & (GW 322 / PBW 498) & Indore & $22^{\circ} 43^{\prime} \mathrm{N}$ & $75^{\circ} 51^{\prime} \mathrm{E}$ & 550 \\
G 9 & HI 8808 & (HI 8680/ HI 8663) & Jabalpur & $23^{\circ} 10^{\prime} \mathrm{N}$ & $79^{\circ} 55^{\prime} \mathrm{E}$ & 403 \\
G 10 & HI 8807 & (HI 8695/ HI 8663// HI 8663) & Powarkheda & $22^{\circ} 70^{\prime} \mathrm{N}$ & $77^{\circ} 73^{\prime} \mathrm{E}$ & 308 \\
& & & Udaipur & $24^{\circ} 34^{\prime} \mathrm{N}$ & $73^{\circ} 41^{\prime} \mathrm{E}$ & 585 \\
& & & Kota & $25^{\circ} 12^{\prime} \mathrm{N}$ & $75^{\circ} 51^{\prime} \mathrm{E}$ & 271 \\
& & & Bilaspur & $22^{\circ} 4^{\prime} \mathrm{N}$ & $82^{\circ} 9^{\prime} \mathrm{E}$ & 264 \\
& & Jagdalpur & $19^{\circ} 4^{\prime} \mathrm{N}$ & $82^{\circ} 1^{\prime} \mathrm{E}$ & 552 \\
\end{tabular}

Table 2. Parentage details of genotypes and environmental conditions (2019-20).

\begin{tabular}{|c|c|c|c|c|c|c|}
\hline Code & Genotype & Parentage & Environments & Latitude & Longitude & Altitude \\
\hline G 1 & HI1634 & (GW322/PBW498) & Anand & $22^{\circ} 33^{\prime} \mathrm{N}$ & $72^{\circ} 56^{\prime} \mathrm{E}$ & 39 \\
\hline G 2 & HD2932 & (KAUZ/STAR//HD2643) & Bardoli & $21^{\circ} 7^{\prime} \mathrm{N}$ & $73^{\circ} 6^{\prime} \mathrm{E}$ & 22 \\
\hline G 3 & MP3336 & (HD 2402/GW 173) & Junagarh & $21^{\circ} 30^{\prime} \mathrm{N}$ & $70^{\circ} 27^{\prime} \mathrm{E}$ & 90 \\
\hline G 4 & HD2864 & (DL509-2/DL377-8) & S.K.Nagar & $21^{\circ} 18^{\prime} \mathrm{N}$ & $72^{\circ} 85 \mathrm{E}$ & 11 \\
\hline \multirow[t]{12}{*}{ G 5} & CG1029 & (HW2004/PHS725) & Vijapur & $23^{\circ} 33^{\prime} \mathrm{N}$ & $72^{\circ} 45^{\prime} \mathrm{E}$ & 129.4 \\
\hline & & & Sanosara & $21^{\circ} 72^{\prime} \mathrm{N}$ & $71^{\circ} 76^{\prime} \mathrm{E}$ & 89 \\
\hline & & & Gwalior & $26^{\circ} 13^{\prime} \mathrm{N}$ & $78^{\circ} 10^{\prime} \mathrm{E}$ & 211 \\
\hline & & & Jabalpur & $23^{\circ} 10^{\prime} \mathrm{N}$ & $79^{\circ} 55^{\prime} \mathrm{E}$ & 403 \\
\hline & & & Powarkheda & $22^{\circ} 70 \mathrm{~N}$ & $77^{\circ} 73 \mathrm{E}$ & 308 \\
\hline & & & Indore & $22^{\circ} 43^{\prime} \mathrm{N}$ & $75^{\circ} 51^{\prime} \mathrm{E}$ & 550 \\
\hline & & & Udaipur & $24^{\circ} 34^{\prime} \mathrm{N}$ & $73^{\circ} 41^{\prime} \mathrm{E}$ & 600 \\
\hline & & & Mandor & & & \\
\hline & & & Bilaspur & $22^{\circ} 4^{\prime} \mathrm{N}$ & $82^{\circ} 9^{\prime} \mathrm{E}$ & 206 \\
\hline & & & Jagdalpur & $19^{\circ} 4^{\prime} \mathrm{N}$ & $82^{\circ} 1^{\prime} \mathrm{E}$ & 552 \\
\hline & & & Ambikapur & $23^{\circ} 6^{\prime} \mathrm{N}$ & $83^{\circ} 11^{\prime} \mathrm{E}$ & 623 \\
\hline & & & IGKV-Raipur & $21^{\circ} 15^{\prime} \mathrm{N}$ & $81^{\circ} 37^{\prime} \mathrm{E}$ & 289 \\
\hline
\end{tabular}

values IPCA1, ASV1, MASV1, ASV, WAASB values. Measures MHPRVG and PRVG expressed direct relation with SI only and negative correlation with remaining measures. Only indirect relations were observed for SI measure. WAASB measure exhibited direct relationships with other stability measures as well negative with SI, PRVG, MHPRVG and yield. All AMMI based measures Za, SIPC, EV, ASV, ASV1, MASV1, MASV and $A S T A B$ achieved only positive correlation values among themselves and with others. ASTAB had an indirect relation with SI, PRVG, MHPRVG and yield. Negative correlations of SIPC with SI, PRVG, MHPRVG and yield were of low magnitude. Indirect relations of Za observed with SI, PRVG, MHPRVG and yield of large negative values. Same behaviour of negative correlations had displayed by IPCA1, ASV1, MASV1, ASV and MASV also.

\section{Second year of study (2019-20)}

AMMI analysis: AMMI analysis observed highly significant effects of the environment (E), GxE interaction and genotypes $(G)$. Diversity of environmental conditions had been reflected by $84.8 \%$ of the total sum of squares due to treatments explained by environments only. Genotypes explained $0.7 \%$ of the total sum of squares, whereas GXE interaction explained $6.4 \%$ of treatment variation in yield (Table 4). The larger mag- 
Table 3. AMMI analysis of wheat genotypes (2018-19).

\begin{tabular}{|c|c|c|c|c|c|c|}
\hline Source & $\begin{array}{l}\text { Degree of } \\
\text { freedom }\end{array}$ & $\begin{array}{l}\text { Mean Sum } \\
\text { of Squares }\end{array}$ & $\begin{array}{l}\text { Level of } \\
\text { significance }\end{array}$ & $\begin{array}{l}\text { Proportional } \\
\text { contribution of } \\
\text { factors }\end{array}$ & $\begin{array}{l}\text { GxE interaction } \\
\text { Sum of Squares } \\
(\%)\end{array}$ & $\begin{array}{l}\text { Cumulative Sum of } \\
\text { Squares } \\
(\%) \text { by IPCA's }\end{array}$ \\
\hline Treatments & 159 & 755.10 & $* * *$ & 91.79 & & \\
\hline Genotype (G) & 9 & 420.28 & $* * *$ & 2.89 & & \\
\hline Environment ( $\mathrm{E}$ ) & 15 & 6932.99 & $* * *$ & 79.51 & & \\
\hline GxE interaction & 135 & 90.98 & $* * *$ & 9.39 & & \\
\hline IPC1 & 23 & 174.67 & $* * *$ & & 32.71 & 32.71 \\
\hline IPC2 & 21 & 124.08 & $* * *$ & & 21.21 & 53.92 \\
\hline IPC3 & 19 & 124.29 & $* * *$ & & 19.23 & 73.15 \\
\hline IPC4 & 17 & 64.79 & $* * *$ & & 8.97 & 82.11 \\
\hline IPC5 & 15 & 54.82 & $* * *$ & & 6.69 & 88.81 \\
\hline IPC6 & 13 & 45.84 & * & & 4.85 & 93.66 \\
\hline IPC7 & 11 & 50.77 & 0.15 & & 4.55 & 98.21 \\
\hline Residual & 16 & 13.77 & 0.87 & & & \\
\hline Error & 480 & 22.37 & & & & \\
\hline Total & 639 & 204.69 & & & & \\
\hline
\end{tabular}

Table 4. AMMI analysis of wheat genotypes (2019-20).

\begin{tabular}{lllllll}
\hline Source & $\begin{array}{l}\text { Degree } \\
\text { of free- } \\
\text { dom }\end{array}$ & $\begin{array}{l}\text { Mean } \\
\text { Sum of } \\
\text { Square } \\
\text { s }\end{array}$ & $\begin{array}{l}\text { Level of } \\
\text { signifi- } \\
\text { cance }\end{array}$ & $\begin{array}{l}\text { Proportional con- } \\
\text { tribution of fac- } \\
\text { tors }\end{array}$ & $\begin{array}{l}\text { GxE interaction } \\
\text { Sum of Squares } \\
\text { (\%) }\end{array}$ & $\begin{array}{l}\text { Cumulative Sum of } \\
\text { Squares } \\
\text { (\%) }) \text { by IPCA's }\end{array}$ \\
\hline Treatments & 79 & 591.81 & $* * *$ & 91.91 & \\
Genotype (G) & 4 & 93.61 & $* * *$ & 0.74 & & \\
Environment (E) & 15 & 2876.02 & $* * *$ & 84.80 & & 45.12 \\
GxE interaction & 60 & 53.97 & $* * *$ & 6.37 & 45.12 & 90.47 \\
IPC1 & 18 & 81.18 & $* * *$ & & 26.12 & 19.23 \\
IPC2 & 16 & 52.86 & $* * *$ & & & \\
IPC3 & 14 & 44.47 & $* *$ & & & \\
Residual & 12 & 25.72 & 0.12 & & & \\
Error & 240 & 17.15 & & & & \\
Total & 319 & 159.47 & & & & \\
\hline
\end{tabular}

Table 5. Measures of stability as per AMMI analysis (2018-19).

\begin{tabular}{lllllllllllllll}
\hline $\begin{array}{l}\text { Geno- } \\
\text { type }\end{array}$ & IPCA1 & $\begin{array}{l}\text { MASV } \\
\mathbf{1}\end{array}$ & MASV & ASV1 & ASV & Za & EV & SIPC & $\begin{array}{l}\text { ASTA } \\
\text { B }\end{array}$ & $\begin{array}{l}\text { WAAS } \\
\text { B }\end{array}$ & SI & $\begin{array}{l}\text { MHPRV } \\
\text { G }\end{array}$ & PRVG & Yield \\
\hline G 1 & 0.90 & 6.25 & 5.14 & 1.98 & 1.80 & 17.74 & 0.037 & 7.52 & 68.62 & 1.194 & 36.59 & 1.028 & 1.033 & 51.07 \\
G 2 & 1.66 & 6.32 & 5.20 & 2.93 & 2.50 & 19.18 & 0.039 & 7.73 & 78.27 & 1.325 & 46.74 & 0.990 & 0.995 & 48.81 \\
G 3 & 0.05 & 5.79 & 5.53 & 3.14 & 3.14 & 16.26 & 0.063 & 7.42 & 103.19 & 1.039 & 73.27 & 0.945 & 0.958 & 47.18 \\
G 4 & 3.24 & 6.66 & 5.71 & 5.20 & 4.27 & 23.60 & 0.057 & 9.55 & 127.25 & 1.647 & 40.57 & 0.950 & 0.964 & 47.45 \\
G 5 & 0.87 & 7.92 & 6.52 & 2.88 & 2.77 & 22.17 & 0.053 & 9.04 & 115.40 & 1.507 & 7.09 & 1.066 & 1.076 & 52.92 \\
G 6 & 1.64 & 6.38 & 5.13 & 2.58 & 2.10 & 17.66 & 0.042 & 7.27 & 74.66 & 1.201 & 87.53 & 0.891 & 0.898 & 44.15 \\
G 7 & 0.28 & 6.83 & 5.92 & 0.53 & 0.46 & 16.00 & 0.063 & 8.05 & 84.26 & 0.978 & 56.46 & 1.005 & 1.012 & 49.86 \\
G 8 & 1.91 & 6.20 & 5.58 & 2.94 & 2.37 & 16.88 & 0.062 & 8.10 & 91.29 & 1.088 & 35.41 & 1.046 & 1.053 & 51.95 \\
G 9 & 1.68 & 4.99 & 4.52 & 3.09 & 2.68 & 19.16 & 0.052 & 8.34 & 77.69 & 1.271 & 46.60 & 0.988 & 0.996 & 49.19 \\
G 10 & 2.76 & 4.84 & 4.11 & 4.25 & 3.42 & 13.40 & 0.032 & 5.29 & 73.52 & 0.954 & 55.12 & 1.007 & 1.015 & 50.20 \\
\hline
\end{tabular}


Table 6. Measures of stability as per AMMI analysis (2019-20).

\begin{tabular}{|c|c|c|c|c|c|c|c|c|c|c|c|c|c|c|}
\hline & IPCA1 & MASV1 & MASV & ASV1 & ASV & $\mathrm{Za}$ & EV & SIPC & ASTAB & WAASB & SI & $\begin{array}{l}\text { MHPR } \\
\text { VG }\end{array}$ & PRVG & Yield \\
\hline$\overline{G 1}$ & 0.13 & 2.78 & 2.77 & 0.34 & 0.31 & 16.02 & 0.101 & 3.12 & 37.79 & 0.817 & 67.58 & 0.997 & 0.999 & 52.84 \\
\hline G 2 & 1.97 & 5.87 & 5.07 & 4.42 & 3.83 & 31.73 & 0.127 & 5.14 & 67.66 & 1.819 & 19.97 & 0.990 & 0.994 & 52.21 \\
\hline G 3 & 3.19 & 5.52 & 4.21 & 5.51 & 4.20 & 25.62 & 0.090 & 3.60 & 63.35 & 1.562 & 8.96 & 0.958 & 0.963 & 51.21 \\
\hline G 4 & 0.95 & 2.72 & 2.50 & 1.65 & 1.26 & 18.88 & 0.070 & 3.31 & 28.82 & 1.030 & 68.73 & 1.009 & 1.012 & 53.27 \\
\hline G 5 & 2.04 & 5.55 & 4.74 & 4.34 & 3.69 & 31.23 & 0.112 & 5.04 & 61.29 & 1.793 & 65.88 & 1.027 & 1.032 & 54.46 \\
\hline
\end{tabular}

Table 7. Simultaneous ranks of genotypes as per yield and AMMI based measures (2018-19).

\begin{tabular}{|c|c|c|c|c|c|c|c|c|c|c|c|c|c|c|}
\hline Genotype & IPCA1 & MASV1 & MASV & ASV1 & ASV & $\mathrm{Za}$ & EV & SIPC & ASTAB & WAASB & SI & $\begin{array}{l}\text { MHPR } \\
\text { VG } \\
\end{array}$ & PRVG & Yield \\
\hline HD 2932 & 7 & 8 & 7 & 5 & 5 & 9 & 5 & 7 & 4 & 5 & 8 & 3 & 3 & 3 \\
\hline HD 2864 & 13 & 13 & 12 & 12 & 12 & 15 & 10 & 12 & 12 & 8 & 5 & 6 & 7 & 7 \\
\hline MP 3336 & 10 & 12 & 15 & 17 & 17 & 12 & 19 & 12 & 17 & 3 & 2 & 9 & 9 & 9 \\
\hline MP 4010 & 18 & 16 & 16 & 18 & 18 & 18 & 15 & 18 & 18 & 10 & 7 & 8 & 8 & 8 \\
\hline CG 1029 & 4 & 11 & 11 & 5 & 8 & 10 & 7 & 10 & 10 & 9 & 10 & 1 & 1 & 1 \\
\hline UAS 3002 & 15 & 17 & 13 & 13 & 13 & 15 & 14 & 12 & 13 & 6 & 1 & 10 & 10 & 10 \\
\hline HI 1633 & 7 & 14 & 14 & 6 & 6 & 7 & 14 & 11 & 11 & 2 & 3 & 5 & 5 & 5 \\
\hline HI 1634 & 10 & 6 & 9 & 8 & 6 & 6 & 10 & 9 & 9 & 4 & 9 & 2 & 2 & 2 \\
\hline HI 8808 & 13 & 8 & 8 & 13 & 12 & 13 & 11 & 14 & 10 & 7 & 6 & 7 & 6 & 6 \\
\hline HI 8807 & 13 & 5 & 5 & 13 & 13 & 5 & 5 & 5 & 6 & 1 & 4 & 4 & 4 & 4 \\
\hline
\end{tabular}

Table 8. Simultaneous ranks of genotypes as per yield and AMMI based measures (2019-20).

\begin{tabular}{|c|c|c|c|c|c|c|c|c|c|c|c|c|c|c|}
\hline $\begin{array}{l}\text { Geno- } \\
\text { type }\end{array}$ & IPCA1 & MASV1 & MASV & ASV1 & ASV & $\mathrm{Za}$ & EV & SIPC & $\begin{array}{l}\text { ASTA } \\
\text { B }\end{array}$ & $\begin{array}{l}\text { WAA } \\
\text { SB }\end{array}$ & SI & $\begin{array}{l}\text { MHPR } \\
\text { VG }\end{array}$ & PRVG & Yield \\
\hline HI1634 & 4 & 5 & 5 & 4 & 4 & 4 & 6 & 4 & 5 & 1 & 2 & 3 & 3 & 3 \\
\hline HD2932 & 7 & 9 & 9 & 8 & 8 & 9 & 9 & 9 & 9 & 5 & 4 & 4 & 4 & 4 \\
\hline MP3336 & 10 & 8 & 8 & 10 & 10 & 8 & 7 & 8 & 9 & 3 & 5 & 5 & 5 & 5 \\
\hline HD2864 & 4 & 3 & 3 & 4 & 4 & 4 & 3 & 4 & 3 & 2 & 1 & 2 & 2 & 2 \\
\hline CG1029 & 5 & 5 & 5 & 4 & 4 & 5 & 5 & 5 & 4 & 4 & 3 & 1 & 1 & 1 \\
\hline
\end{tabular}

nitude of GxE interaction (sum of squares) than genotypes indicated the presence of genotypic differences across environments and complex GxE interaction for wheat yield. Further partitioning of GxE interaction through the AMMI analysis revealed that the first three multiplicative terms (IPCA1, IPCA2 and IPCA3) were significant and explained $45.1 \%, 26.1 \%$ and $19.2 \%$ of interaction sum of squares, respectively. Approximately $90.5 \%$ of the sum of squares accounted by three PC's and $9.5 \%$ left for the residual or noise, which is not interpretable and thus discarded.

Stability measures: Lower values of EV anticipated stable performance of G4, G3 genotypes. The sums of the absolute value of the IPC scores (SIPC) identified $\mathrm{G} 1$ followed by $\mathrm{G} 4$ as the stable genotypes as compared to whereas G2 (Table 6). The absolute value of the relative contribution of IPCs to the interaction $(\mathrm{Za})$ revealed $\mathrm{G} 1$, and $\mathrm{G} 4$ genotypes as of stable behaviour in descending order of stability. Minimum values of ASV measure showed by G1, G4 genotype would show the stable performance. ASV1 selected G1, G4 for their stable yield behaviour. The values of MASV showed that the genotypes $\mathrm{G} 4$ and G1 were most and MASV1 considered G4, G1 would be genotypes of stable yield. AMMI-based stability parameter (ASTAB) identified genotypes G4 and G1 with the least value of the measure for stable performance in this study. The lowest value of WAASB measure had achievement by G1 and G4 as desirable genotypes for considered locations of the zone. Maximum yield expressed by G5 followed by G4 and least variation observed from 51.2 to $54.5 \mathrm{q} / \mathrm{ha}$ among genotypes. Stable performance of genotypes G3, G2 assured by values of PRVG measure while MHPRVG measure selected G3, G2 along with least stable yield of G5. Superiority index had observed lower values by genotypes G3 and G2, whereas large value by G4. Least value of absolute IPCA1 expressed by G1, G4 and higher value achieved by G3.

Simultaneous ranks of genotypes as per AMMI based stability and yield: Simultaneous ranks as per least values of IPCA1 measure considered HI1634 and HD2864 genotypes with stable high yield, whereas high values for MP3336 suggested as least stable yield (Table 8). EV measure identified HD2864 and CG1029 for stable performance, whereas SPIC values favoured HI1634 and HD2864. HD2864 and HI1634 genotypes possessed a lower value of $\mathrm{Za}$ measure. 
Table 9. Loadings of stability measures as per two PC's (2018-19).

\begin{tabular}{lll}
\hline Measure & PC1 & PC2 \\
\hline IPCA1 & 0.235 & 0.095 \\
MASV1 & 0.257 & -0.186 \\
MASV & 0.257 & -0.198 \\
ASV1 & 0.276 & 0.153 \\
ASV & 0.277 & 0.085 \\
Za & 0.277 & -0.289 \\
EV & 0.278 & 0.050 \\
SIPC & 0.270 & -0.327 \\
ASTAB & 0.300 & -0.139 \\
WAASB & 0.110 & -0.581 \\
SI & -0.195 & -0.480 \\
MHPRVG & 0.310 & 0.194 \\
PRVG & 0.313 & 0.186 \\
Yield & 0.313 & 0.186 \\
\% variance & 63.87 & 16.12 \\
\hline
\end{tabular}

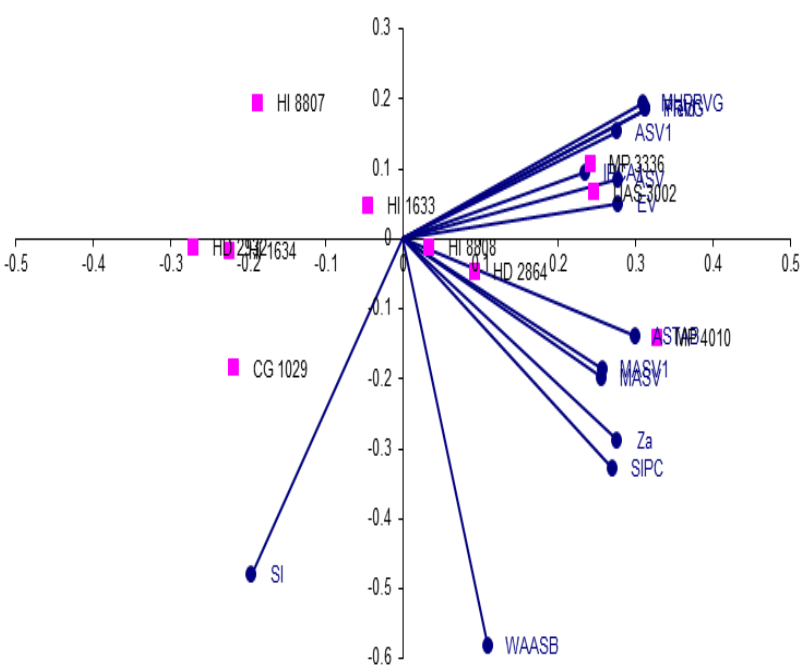

Fig 1. Biplot graphical analysis of stability measures for wheat genotypes evaluated under MET (2018-19).

Least values of ASV and ASV1 pointed towards CG1029 and HD2864 wheat genotypes. Modified AMMI stability Value measure MASV along with MASV1 selected, HD2864, CG1029 genotypes of choice for these locations of the zone. WAASB measure observed suitability of HI1634 and HD2864 genotypes for the considered locations of this zone. Superiority index while weighting 0.65 and 0.35 for yield and stability found HD2864 and HI1634 as of stable performance along with high yield. PRVG as well as MHPRVG measures observed suitability of CG1029 and HD2864 while MP3336 as unstable wheat genotypes. Moreover, the average yield of genotypes ranked CG1029 and HD2864 as of the order of choice. More or less all measures identified CG1029, and HD2864 genotypes for stable and high yield as
Table 10. Loadings of stability measures as per two PC's (2019-20).

\begin{tabular}{lll}
\hline Measure & PC1 & PC2 \\
\hline IPCA1 & 0.267 & -0.079 \\
MASV1 & 0.283 & 0.146 \\
MASV & 0.283 & 0.146 \\
ASV1 & 0.283 & -0.102 \\
ASV & 0.283 & -0.102 \\
Za & 0.281 & 0.192 \\
EV & 0.255 & 0.153 \\
SIPC & 0.281 & 0.192 \\
ASTAB & 0.292 & -0.019 \\
WAASB & 0.159 & 0.649 \\
SI & 0.270 & 0.123 \\
MHPRVG & 0.259 & -0.363 \\
PRVG & 0.259 & -0.363 \\
Yield & 0.259 & -0.363 \\
\% variance & 82.86 & 11.44 \\
\hline
\end{tabular}

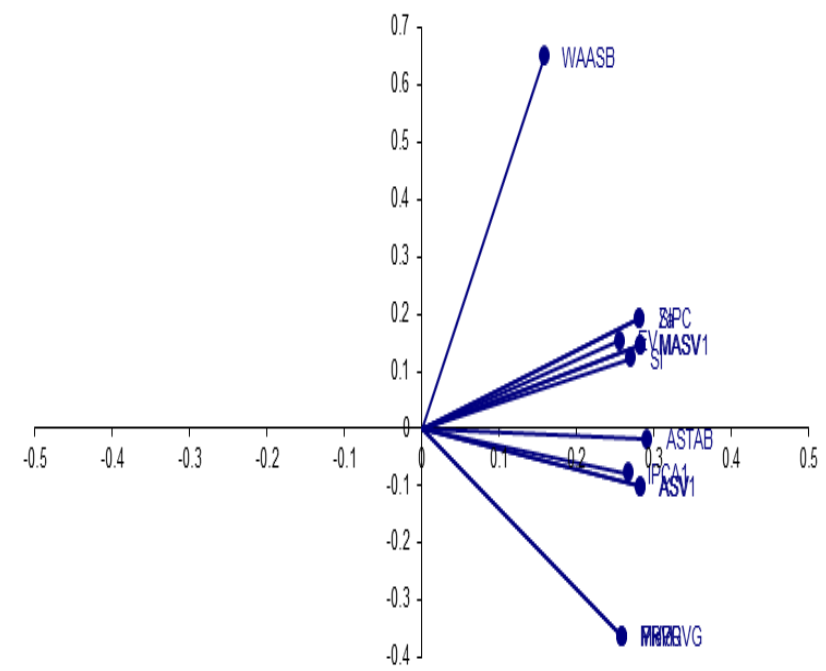

Fig 2. Biplot graphical analysis of stability measures for wheat genotypes evaluated under MET (2019-20).

per considered locations of this zone.

Biplot graphs: Biplot graphical analysis considered the first two significant principal component analysis as the loadings of stability measures for evaluated wheat genotypes were tabulated in table 10 . The first two PCAs explained $94.3 \%$ of the variation of the original variables. $\mathrm{PC} 1$ and $\mathrm{PC} 2$ axes distinguish measures into three groups (Fig 2). SI clubbed with EV, SIPC, MASV1, Za measures. Yield grouped with PRVG and MHPRVG measures. AMMI based measures IPCA1, ASV1 and ASTAB clustered in a separate cluster. Stability measure WAASB was observed as outliers in biplot analysis.

Association analysis: The average yield of genotypes had positive values of higher magnitude with SI, MHPRVG and PRVG values. Moreover other 
Verma A. and Singh G.P. / J. Appl. \& Nat. Sci. 12(4): 541 - 549 (2020)

Table 11. Association analysis of SI with other stability measures (2018-19).

\begin{tabular}{|c|c|c|c|c|c|c|c|c|c|c|c|c|c|}
\hline Measure & $\overline{\text { MASV1 }}$ & MASV & ASV1 & ASV & $\mathrm{Za}$ & $\overline{E V}$ & SIPC & ASTAB & $\begin{array}{l}\text { WAAS } \\
\text { B }\end{array}$ & SI & $\begin{array}{l}\text { MHPRV } \\
\text { G }\end{array}$ & PRVG & Yield \\
\hline$\overline{\mathrm{IPCA} 1}$ & -0.294 & -0.418 & 0.784 & 0.646 & 0.232 & -0.348 & -0.033 & 0.128 & 0.374 & -0.092 & -0.134 & -0.127 & -0.119 \\
\hline MASV1 & & 0.927 & -0.278 & -0.228 & 0.589 & 0.321 & 0.642 & 0.534 & 0.510 & -0.459 & 0.249 & 0.260 & 0.225 \\
\hline MASV & & & -0.269 & -0.187 & 0.535 & 0.629 & 0.716 & 0.679 & 0.408 & -0.425 & 0.257 & 0.280 & 0.248 \\
\hline ASV1 & & & & 0.979 & 0.341 & -0.161 & 0.035 & 0.465 & 0.472 & -0.098 & -0.206 & -0.174 & -0.170 \\
\hline ASV & & & & & 0.378 & -0.098 & 0.078 & 0.537 & 0.493 & -0.127 & -0.188 & -0.151 & -0.149 \\
\hline $\mathrm{Za}$ & & & & & & 0.216 & 0.876 & 0.681 & 0.978 & -0.518 & 0.013 & 0.037 & 0.012 \\
\hline EV & & & & & & & 0.605 & 0.606 & 0.042 & -0.075 & 0.040 & 0.072 & 0.062 \\
\hline SIPC & & & & & & & & 0.691 & 0.762 & -0.492 & 0.111 & 0.135 & 0.111 \\
\hline ASTAB & & & & & & & & & 0.635 & -0.383 & 0.032 & 0.083 & 0.063 \\
\hline WAASB & & & & & & & & & & -0.502 & -0.018 & 0.005 & -0.019 \\
\hline SI & & & & & & & & & & & -0.853 & -0.866 & -0.855 \\
\hline MHPRVG & & & & & & & & & & & & 0.998 & 0.997 \\
\hline PRVG & & & & & & & & & & & & & 0.999 \\
\hline
\end{tabular}

Table 12. Association analysis of SI with other stability measures (2019-20).

\begin{tabular}{|c|c|c|c|c|c|c|c|c|c|c|c|c|c|}
\hline Measure & MASV1 & MASV & ASV1 & $\overline{A S V}$ & $\mathrm{Za}$ & EV & SIPC & ASTAB & $\begin{array}{l}\text { WAAS } \\
\text { B }\end{array}$ & $\mathrm{SI}$ & $\begin{array}{l}\text { MHPR } \\
\text { VG }\end{array}$ & PRVG & Yield \\
\hline$\overline{\mathrm{IPCA} 1}$ & 0.846 & 0.717 & 0.975 & 0.943 & 0.709 & 0.173 & 0.436 & 0.793 & 0.791 & -0.780 & -0.495 & -0.451 & -0.422 \\
\hline $\begin{array}{l}\text { MASV1 } \\
\text { MASV }\end{array}$ & & 0.977 & $\begin{array}{l}0.937 \\
0.848\end{array}$ & $\begin{array}{l}0.966 \\
0.900\end{array}$ & $\begin{array}{l}0.943 \\
0.967\end{array}$ & $\begin{array}{l}0.660 \\
0.790\end{array}$ & $\begin{array}{l}0.805 \\
0.897\end{array}$ & $\begin{array}{l}0.983 \\
0.971\end{array}$ & $\begin{array}{l}0.968 \\
0.966\end{array}$ & $\begin{array}{l}-0.698 \\
-0.598\end{array}$ & $\begin{array}{l}-0.241 \\
-0.101\end{array}$ & $\begin{array}{l}-0.198 \\
-0.062\end{array}$ & $\begin{array}{l}-0.207 \\
-0.088\end{array}$ \\
\hline ASV1 & & & & 0.993 & 0.846 & 0.359 & 0.622 & 0.885 & 0.906 & -0.757 & -0.375 & -0.328 & -0.320 \\
\hline ASV & & & & & 0.901 & 0.450 & 0.708 & 0.916 & 0.948 & -0.729 & -0.302 & -0.256 & -0.257 \\
\hline $\mathrm{Za}$ & & & & & & 0.690 & 0.944 & 0.893 & 0.992 & -0.489 & 0.056 & 0.099 & 0.062 \\
\hline EV & & & & & & & 0.797 & 0.735 & 0.631 & -0.298 & 0.091 & 0.105 & 0.056 \\
\hline SIPC & & & & & & & & 0.765 & 0.895 & -0.254 & 0.309 & 0.343 & 0.283 \\
\hline ASTAB & & & & & & & & & 0.915 & -0.728 & -0.312 & -0.274 & -0.278 \\
\hline WAASB & & & & & & & & & & -0.563 & -0.040 & 0.005 & -0.022 \\
\hline SI & & & & & & & & & & & 0.835 & 0.813 & 0.839 \\
\hline MHPRVG & & & & & & & & & & & & 0.999 & 0.983 \\
\hline PRVG & & & & & & & & & & & & & 0.986 \\
\hline
\end{tabular}

measures had maintained only negative correlations. Similar nature of MHPRVG and PRVG observed with other stability measures (table 12). Values of $\mathrm{SI}$ measure had expressed only indirect relations of high degree with measures except with yield, PRVG and MHPRVG values. WAASB had positive relations with most of the measures and of negative correlation values with SI, yield and MHPRVG values. AMMI based measures, ASTAB, SIPC, EV, Za, ASV, ASV1, MASV, MASV1 expressed only positive correlation values themselves and with others. The negative correlation of AMMI based measures with SI, MHPRVG, PRVG and yield was also observed.

\section{Conclusion}

Highly significant effects of environment (E), GxE interaction and genotypes (G) observed by AMMI analysis during 2018-19 and 2019-20 study years. Complex GxE interaction for wheat yield had been judged by higher sum of squares for GxE interaction as compared to genotypes. Stability measures by simultaneous use of AMMI model and yield would be more meaning full and useful as compared to measures consider either the AMMI or yield of genotypes only. Superiority index significantly correlated with yield and analytic measures of yield. Measures considering all significant interaction principal components i.e. MASV, MASV1, WAAB and SI would be used to identify stable high-yielding genotypes.

\section{ACKNOWLEDGEMENTS}

The wheat genotypes were evaluated at research fields at coordinated centers of AICW\&BIP across the country. First author sincerely acknowledges the hard work of all the staff for field evaluation and data recording of wheat genotypes.

\section{Conflict of interest}

The authors declare that they have no conflict of interest.

\section{REFERENCES}

1. Adjebeng-Danquah, J., Manu-Aduening, J., Gracen V.E., Asante I.K., and Offei, S.K. (2017). AMMI stability analysis and estimation of genetic parameters for growth and yield components in cassava in the forest and guinea savannah ecologies of Ghana. Int. J. Agron. 2017:1-10.

2. Ajay, B. C., Aravind J., Fiyaz R. Abdul, Kumar Narendra, Lal Chuni, Gangadhar K., Kona Praveen, Dagla M. C. and Bera S. K. (2019) Rectification of modified AMMI stability 
value (MASV). Indian J. Genet., 79(4) 726-731

3. Balestre, M., Von Pinho R.G., Souza J.C., and Oliveira R.L.( 2009). Genotypic stability and adaptability in tropical maize based on AMMI and GGE biplot analysis. Genet. Mol. Res. 8:1311-1322.

4. Bocianowski, J., Niemann J., and Nowosad K. (2019). Genotype-by environment interaction for seed quality traits in interspecific cross-derived Brassica lines using additive main effects and multiplicative interaction model. Euphytica 215(7):1-13.

5. Bornhofen, E., Benin G., Storck L., Woyann L.G., Duarte T., Stoco M.G., and Marchioro S.V.. (2017). Statistical methods to study adaptability and stability of wheat genotypes. Bragantia 76:1-10.

6. Farshadfar, E. 2008. Incorporation of AMMI stability value and grain yield in a single nonparametric index (GSI) in bread wheat. Pak. J. Biol. Sci. 11:1791-1796.

7. Farshadfar, E., Mahmodi N., and Yaghotipoor A.. 2011. AMMI stability value and simultaneous estimation of yield and yield stability in bread wheat (Triticum aestivum L.). Aust. J. Crop Sci. 5:1837-1844.

8. Gauch, H.G. (2013). A simple protocol for AMMI analysis of yield trials. Crop Sci. 53:1860-1869.

9. Kang, M.S. (1993). Simultaneous selection for yield and stability in crop performance trials: Consequences for growers. Agronomy Journal 85:754-757.

10. Olivoto, T. (2018). WAASB data, Mendeley Data, v2. doi. org/10.17632/2sjz32k3s3.2

11.Olivoto, T. (2019). Metan: multi environment trials analysis. $\mathrm{R}$ package version 1.1.0. https://github.com/ TiagoOlivoto/metan.

12. Olivoto, T., Lucio A. Dal'Col, Gonzalez, Silva J.A. da, and Marchioro V.S. (2019). Mean performance and stability in multi-environment trials I: Combining features of AMMI and BLUP techniques. Agronomy Journal . 111:1-12.
13.Oyekunle, M., Menkir A., Mani H., Olaoye G., Usman I.S., Ado S.G. (2017). Stability analysis of maize cultivars adapted to tropical environments using AMMI analysis. Cereal Res. Commun. 45:336-345.

14.Purchase, J.L., Hatting H., and Deventer C.S. van. (2000). Genotype $\times$ environment interaction of winter wheat (Triticum aestivum L.) in South Africa: II. Stability analysis of yield performance. S. Afr. J. Plant Soil 17:101-107.

15.Ramburan, S., Zhou M., and Labuschagne M. (2011). Interpretation of genotype $\times$ environment interactions of sugarcane: Identifying significant environmental factors. Field Crops Res. 124:392-399.

16.Rao, A.R., and Prabhakaran V.T. (2005). Use of AMMI in simultaneous selection of genotypes for yield and stability. Journal of the Indian Society of Agricultural Statistics 59:76-82.

17.Resende, M.D.V. and Duarte, J.B. (2007). Precision and Quality Control in Variety Trials. Pesquisa Agropecuaria Tropical , 37: 182-194.

18.Sneller, C.H., Norquest L. Kilgore-, and Dombek D. (1997). Repeatability of yield stability statistics in soybean. Crop Sci. 37:383-390.

19.Veenstra, L.D., Santantonio N., Jannink J.-L., and Sorrells M.E. (2019). Influence of genotype and environment on wheat grain fructan content. Crop Sci. 59:190-198.

20.Zali, H., Farshadfar E., Sabaghpour S.H., and Karimizadeh R. (2012). Evaluation of genotype $\times$ environment interaction in chickpea using measures of stability from AMMI model. Ann. Biol. Res. 3:3126-3136.

21.Zhang, Z., Lu C., and Xiang Z.H. (1998). Analysis of variety stability based on AMMI model. Acta Agronomica Sinica 24:304-309.

22.Zobel, R.W., Wright M.J., and Gauch H.G. Jr. (1988). Statistical analysis of yield trial. Agronomy Journal 80:388393. 